\title{
KAJIAN SOSIOPRAGMATIK TENTANG PENGGUNAAN KATEGORI FATIS BAHASA SASAK DALAM KESANTUNAN TINDAK TUTUR MASYARAKAT LOMBOK
}

\author{
${ }^{1}$ Habiburrahman, ${ }^{2}$ Rudi Arahman* \\ *Program Studi Pendidikan Bahasa Indonesia \\ FKIP Universitas Muhammadiyah Mataram \\ Surel: habibpemuda@gmail.com
}

\begin{abstract}
Abstrak
Kategori fatis yaitu tipe tuturan yang digunakan untuk menciptakan ikatan sosial yang harmonis dengan semata-mata bertukar kata-kata. Dengan demikian, tujuan penelitian ini adalah: 1) untuk mendeskripsikan dan menjelaskan bentuk dan fungsi kategori fatis bahasa Sasak; 2) untuk mendeskripsikan dan menjelaskan nilai dari strategi kesantunan penggunaan bentuk dan fungsi kategori fatis bahasa Sasak. Metode yang digunakan dalam penelitian ini adalah metode deskriptif kualitatif. Data diperoleh melalui teknik observasi yang dibantu teknik perekaman menggunakan handycam. Data penelitian terdiri atas dua jenis, yaitu: (1) data tuturan berupa percakapan masyarakat; dan (2) data catatan lapangan berupa interaksi verbal dan situasi tindak tutur. Berdasarkan hasil penelitian dapat dideskripsikan sebagai berikut: 1) bentuk kategori fatis dalam bahasa Sasak berupa: partikel, kata dan frase. 2) Fungsi kategori fatis dalam bahasa sasak yaitu, untuk memulai percakapan, untuk melakukan gosip, untuk mengalihkan topik, untuk menyatakan empati, untuk mengungkapkan kesantunan, sebagai penegasan, fungsi untuk mengungkapkan ekspresi dan fungsi untuk mengakhiri percakapan. 3) Strategi kesantunan penggunaan bentuk dan fungsi kategori fatis bahasa Sasak, yaitu menggunakan srategi kesantunan negatif dan strategi positif. Beberapa jenis strategi kesantunan tersebut yaitu 1) mengintensifkan perhatian penutur dengan mendramatisasikan peristiwa dan fakta; 2) menunjukkan hal-hal yang dianggap mempunyai kesamaan melalui basa-basi (small talk) dan praanggapan (presupposition); 3) menhindari ketidaksetujuan dengan pura-pura setuju dalam arti persetujuan yang semu; 4) membesarbesarkan perhatian, persetujuan, dan simpati kepada mitratutur; 5) ujaran tindak tutur itu sebagai kesantunan yang bersifat umum; dan 6) menyatakan hubungan secara timbal balik.
\end{abstract}

Kata kunci: kesantunan, bentuk dan fungsi kategori fatis

\section{PENDAHULUAN}

Bahasa digunakan oleh masyarakat penuturnya tidak hanya untuk berkomunikasi antarsesama, namun sebagai ciri atau identitas kebudayaan dari masing-masing daerah penutur. Dalam hal ini, peranan bahasa daerah sangat vital.
Bahasa daerah pada umumnya menjadi bahasa ibu dan identitas dari penuturnya. Keanekaragaman bahasa daerah di Indonesia menjadi kebanggaan yang diwariskan secara turun-temurun oleh setiap penuturnya. 
Dalam penelitian ini, peneliti mengambil aspek bahasa dari unsur dalam yaitu sebuah kajian struktural kategori fatis dalam bahasa Sasak dialek Kuto-kute yang daerah sebarnya di wilayah Kabupaten Lombok Utara. Dalam penelitian ini, kajian akan difokuskan pada aspek bentuk dan fungsi kategori fatis dengan menggunakan kajian sintaksis. Semetara perannya yang dikaitan dengan nilai strategi kesantunan dalam kajian sosiopragmatik. Hal ini sesuai dengan pengertian mengenai ungkapan fatis yaitu tipe tuturan yang digunakan untuk menciptakan ikatan sosial yang harmonis dengan semata-mata bertukar kata-kata. Di Indonesia sendiri salah satu linguis Indonesia yang pertama kali memasukkan kategori ini menjadi salah satu kelas kata adalah Kridalaksana. Kategori fatis adalah kategori yang bertugas memulai, mempertahankan, atau mengukuhkan komunikasi antara pembicara dengan kawan bicara (Kridalaksana, 2008: 114).

Kajian kategori fatis bahasa Sasak telah banyak dilakukan oleh para peneliti, akan tetapi hasil yang didapatkan masih kurang dari harapan karena hanya terbatas pada kajian sintaksis yang belum dikaji dari aspek sosiopragmatik. Di samping itu, karena luasnya kajian bahasa Sasak yang terdiri dari dialek yang berbeda sangat memungkinkan bagi para peneliti $\begin{array}{lrr}\text { melakukan } & \text { penelitian } & \text { sebagai } \\ \text { pengembangan } & \text { khazanah } & \text { ilmu }\end{array}$ pengetahuan. Penelitian bahasa di daerah Kabupaten Lombok Utara belum pernah dilakukan, lebih-lebih dalam hal kategori fatisnya. Oleh sebab itu, peneliti dalam penelitian ini mengangkat permasalahan bahasa Sasak yang sifatnya terbaru. Kategori fatis yang peneliti angkat pada penelitian ini yaitu kategori fatis dalam aspek bentuk dan fungsi kategori fatis bahasa Sasak dialek Kuto-kute yang ada di masyarakat Dusun Bentek Desa Pemenang Barat Kecamatan Pemenang Kabupaten Lombok Utara. Berdasarkan latar belakang yang telah dipaparkan, tujuan dalam penelitian ini sebagai berikut. 1) Peneliti mendeskripsikan dan menjelaskan bentuk dan fungsi kategori fatis dalam bahasa Sasak dialek Kuto-kute di Desa Pemenang Barat Kabupaten Lombok Utara. 2) Peneliti mendeskripsikan dan menjelaskan nilai strategi kesantunan penggunaan bentuk dan fungsi kategori fatis dalam Bahasa Sasak dialek Kuto-kute di Desa Pemenang Barat Kabupaten Lombok Utara.

\section{TINJAUAN PUSTAKA}

\section{Kategori Fatis}

Pada tahun 1920-an Malinowsky yang pertama kali mencetuskan konsep fatis ini dengan konsepnya ungkapan fatis. Konsep bahasa yang menjaga agar 
komunikasi tetap berkesinambungan disebut fatis (Leech dalam Waridin 2008: 39). Dengan demikian, ungkapan fatis yaitu tipe tuturan yang digunakan untuk menciptakan ikatan sosial yang harmonis dengan semata-mata bertukar kata-kata. Jackobson (dalam Waridin 2008: 39) juga menyatakan konsep fatis dibedakan berdasakan fungsinya: yaitu fungsi bahasa untuk memulai komunikasi, mempertahankan komunikasi dan menarik perhatian lawan bicara agar tetap memperhatikan pembicaraan.

Menurut Kridalaksana (2008: 114) kelas kata ini biasanya terdapat konteks dialog atau wawancara bersambutan, yaitu kalimat-kalimat yang diucapkan oleh pembicara dan kawan bicara. Sebagian besar kategori fatis merupakan ciri ragam lisan, karena ragam lisan pada umumnya merupakan ragam non-standar. Maka kebanyakan kategori fatis terdapat dalam kalimat-kalimat non-standar yang banyak mengandung unsur-unsur daerah atau dialek regional.

1) Bentuk dan Jenis Kategori Fatis

Kridalaksana (2008, 116-117) mengklasifikasikan kategori fatis dalam bentuk partikel, kata dan frase. Bentuk fatis biasanya terdapat dalam bahasa lisan yang umumnya merupakan ragam nonstandar, maka kebanyakan kategori fatis terdapat dalam kalimat-kalimat non- standar yang banyak mengandung unsurunsur daerah atau dialek regional. Bentuk dan jenis kategori fatis sebagai berikut.

a. Partikel fatis

Ramlan (dalam Muslich, 2014: 115) menyatakan bahwa kata partikel adalah semua kata yang tidak termasuk golongan kata nominal dan ajektival. Moeliono (1998: 247-249) juga menyatakan partikel penegas meliputi kata yang tidak tertakluk pada perubahan bentuk dan hanya berfungsi menampilkan unsur yang diiringinya.

b. Kata fatis

Kata fatis yaitu kata dalam sebuah kalimat yang bertugas untuk memulai, mempertahankan, dan mengukuhkan komunikasi atau mengukuhkan komunikasi antara pembicara dan pendengar dan biasanya terdapat dalam konteks dialog, lazimnya bentuk fatis digunakan dalam bentuk ragam lisan (Kridalaksana 2008:116).

Bentuk fatis bisa berada di awal kalimat misalnya Kok kamu pergi juga?, ada yang di tengah kalimat, misalnya bukan dia, kok, yang mengambil uang itu!, maupun di akhir kalimat misalnya saya hanya lihat saja, kok!.

Kategori fatis mempunyai wujud bentuk bebas, misalnya; kok, deh, dong, 
ding, halo, kan, kek, lho, mari, nah, sih, toh, ya, dan yah. Kemudian kategori fatis dalam wujud terikat atau dalam wujud partikel, misalnya : -lah, -tah, -kah, -pun.

\section{c. Frase fatis}

Frasa adalah gabungan dua kata atau lebih yang bersifat nonpredikatif. Frase fatis selamat pagi mempunyai fungsi membuka komunikasi yang kemudian membentuk ikatan sosial yang harmonis antara penutur dan mitra tutur. Pada bagian isi komunikasi bentuk fatis digunakan untuk mengukuhkan komunikasi dengan menggunakan partikel pun, kan, sih, lho, dan kata halo. Sedangkan pada bagian penutup terdapat kalimat penutup seperti frase selamat siang. Frase selamat siang digunakan untuk menutup komunikasi dan memutus ikatan sosial yang terjalin antara penutur dan mitra tutur (Moeliono, 1998: 248-249).

2) Fungsi Kategori Fatis

Konsep fatis dibedakan berdasakan fungsinya: yaitu fungsi bahasa untuk memulai komunikasi, mempertahankan komunikasi dan menarik perhatian lawan bicara agar tetap memperhatikan pembicaraan, Jackobson (dalam Waridin 2008: 39).

Fungsi fatis yaitu sebuah wacana berfungsi untuk membuka jalan atau kontak. Fungsi bahasa yang digunakan sebagai basa-basi di dalam kebudayaan sosial, fungsi bahasa ini penting akan tetapi kita harus berhati-hati terhadap sikap berbicara kita kerena berbeda kebudayaan berbeda pula penafsiran penggunaan bahasa, penangkapan sombong, acuh, dari orang lain yang berbeda agama dengan kita akan kita dapatkan jika kita tidak berhatihati ketika menggunakan fungsi dari bahasa ini.

\section{3) Teori Kesantunan}

Sopan santun sering diartikan secara dangkal sebagai suatu 'tindakan yang sekadar beradab' saja, namun makna yang lebih penting yang diperoleh dari sopan santun ialah, sopan santun merupakan mata rantai yang hilang antara $\mathrm{Pk}$ dengan masalah bagaimana mengaitkan daya dengan makna (Leech, 1982:161).

$\begin{array}{clr}\text { Teori } & \text { 'kesantunan' dalam } \\ \text { penelitian ini } & \text { dibedakan dengan } \\ \text { 'kesopanan' dalam kajian sosiolinguitik. }\end{array}$
Kesopanan linguistik memang ditentukan secara kultural. Jelasnya, kaidah-kaidah untuk berperilaku yang sopan berbeda antara satu masyarakat tutur yang satu dengan masyarakat tutur yang lain. Masyarakat tutur yang berbeda memberikan penekanan pada fungsi-fungsi yang berbeda dan mengekspresikan fungsifungsi tertentu secara berbeda pula (Holmes, tanpa tahun:271). 
Strategi kesantunan yang digunakan dalam penelitian ini adalah berdasarkan kajian Brown dan levinson. Untuk mengurangi kekecewaan mitratutur, Brown dan Levinson (1987) menawarkan strategi-strategi berikut untuk tindakan yang melanggar wajah positif dan negatif. Bagaimana bentuk strategi itu, tergantung pada jenis kesantunannya, yaitu kesantunan negatif (ada yang menyebutkan kesantunan deferensia) atau kesantunan positif (ada yang menyebutnya kesantunan afirmatif) (Pranowo, 2012:43).

\section{METODE PENELITIAN}

Dalam penelitian ini peneliti menggunakan metode penelitian kualitatif. Penelitian jenis kualitatif bertujuan untuk memaparkan data sebagaimana adanya. Dalam hal ini, peneliti tidak mempunyai kontrol atas manipulasi langsung terhadap variabel-variabel bebas (Sukardi, 2004:24). Data diperoleh melalui teknik observasi yang dibantu teknik perekaman menggunakan handycam. Data penelitian terdiri atas dua jenis, yaitu: (1) data tuturan berupa percakapan dan (2) data catatan lapangan berupa interaksi verbal dan situasi tindak tutur.

Metode analisis data dilakukan dengan metode identifikasi dan klasifikasi. Data yang telah diklasifikasi kemudian diinterpretasikan. Interpretasi adalah usaha untuk memperjelas arti bahasa dengan cara menguraikan dan mengomentari (Sugiyono, 2010).

\section{HASIL DAN PEMBAHASAN}

Pembahasan ini menekankan pada dimensi kesantunan yang terciptanya dari penggunaan bentuk dan fungsi kategori fatis. Pembahasan ini diuraikan berdasarkan hasil penelitian tentang kajian sosiopragmatik tentang penggunaan kategori fatis bahasa Sasak dalam kesantunan tindak tutur masyarakat Lombok yang berkaitan dengan dua hal, yaitu: 1) bentuk dan fungsi kategori fatis bahasa Sasak; 2) nilai dari strategi kesantunan penggunaan bentuk dan fungsi kategori fatis bahasa Sasak.

\section{1) Bentuk Kategori Fatis pada Masyarakat Sasak}

Berdasarkan penelitian yang telah dilakukan pada wilayah penelitian di Dusun Bentek Desa Pemenang Barat, ditemukan bentuk kategori fatis yaitu berupa partikel fatis, kata fatis dan frase fatis serta fungsi kategori fatis.

Pada bagian ini peneliti akan membahas satu-persatu bentuk-bentuk kategori fatis yang tedapat dalam dialek Kuto-kute pada masyarakat Dusun Bentek Desa Pemenang Barat dengan memperhatikan kata-kata yang digunakan oleh informan yang biasanya menggunakan kategori fatis dalam melakukan komunikasi ataupun interaksi. 


\subsection{Bentuk fatis berupa partikel}

Pada wilayah penelitian Dusun Bentek

Desa Pemenang Barat, terdapat bentuk fatis berupa atau berjenis partikel yang ditemukan adalah sebagai berikut.

(1) Bentuk partikel fatis kan

Bentuk fatis kan merupakan kependekan dari kata tekan yang memiliki arti "bukannya". Partikel fatis ini biasanya digunakan sebagai partikel penanya terhadap lawan bicara.

(2) Bentuk partikel fatis $\mathrm{suh} / \mathrm{seh}$

Bentuk partikel suh dalam dialek Kuto-kute bersinonim dengan partikel seh yang memiliki fungsi yang sama yaitu mempertegas pernyataan. Dalam penggunaannya partikel suh/seh hanya digunakan untuk menekankan perintah kepada lawan bicara.

(3) Bentuk partikel fatis be

Partikel fatis be dalam dialek Kutokute biasanya digunakan untuk kata bantu untuk menyangkal ujaran kawan bicara ataupun untuk memperjelas konstituen tertentu serta memaksa dengan cara membujuk.

(4) Bentuk partikel fatis kah

Bentuk partikel fatis kah merupakan partikel yang biasa digunakan masyarakat Dusun Bentek untuk memberi perintah kepada lawan bicara.
(5) Bentuk partikel fatis dong

Partikel fatis dong biasanya digunakan untuk memberi perintah dengan halus kepada kawan bicara dan sedikit penegasan.

(6) Bentuk partikel fatis $a h$

Bentuk partikel biasanya digunakan dalam kalimat tanya untuk menanyakan kepastian kepada lawan bicara.

(7) Bentuk partikel fatis nah

Partikel fatis nah biasanya digunakan dalam pernyataan seru untuk membenarkan kawan bicara.

(8) Bentuk partikel fatis ne

Partikel fatis ne merupakan partikel penanda dan penunjuk yang digunakan untuk meminta pendapat kawan bicara, dan sebagai penunjuk sesuatu.

(9) Bentuk partikel fatis jek

Partikel jek merupakan partikel seru yang biasa digunakan untuk menekankan konstituen tertentu. Penjelasan ini dapat disimpulkan bahwa partikel jek merupakan partikel seru dalam sebuah pernyataan yang berfungsi sebagai menekankan konstituen tertentu yaitu kata bareh yang bermakna nanti yang dalam fungsi sintaksis sebagai keterangan.

(10) Bentuk partikel fatis $c a$

Partikel ca merupakan partikel fatis yang digunakan sebagai penanda isyarat yang berarti itu. 
(11) Bentuk partikel fatis ono

Partikel ono merupakan partikel fatis yang memiliki fungsi yang sama dengan partikel $c a$ yaitu sebagai isyarat untuk menunjuk sesuatu.

(12) Bentuk partikel fatis poh

Partikel poh merupakan partikel penanya yang berfungsi untuk membentuk kalimat tanya.

(13) Bentuk partikel fatis $e /$ we

Partikel fatis e/we merupakan partikel seru yang biasa digunakan sebagai isyarat untuk memanggil atau memulai pembicaraan lawan bicara.

(14) Bentuk partikel fatis ndeh

Partikel fatis ndeh merupakan partikel fatis penegas yang berfungsi untuk membenarkan pernyataan kawan bicara.

(15)Bentuk partikel fatis wah

Partikel fatis wah merupakan partikel yang digunakan sebagai kata keterangan yang berarti sudah.

(16) Bentuk partikel Be....be

Partikel fatis be...be merupakan partikel fatis gabungan yang terdapat dalam dialek Kuto-kute pada masyarakat Dusun Bentek Desa Pemenang Barat.

(17)Bentuk partikel Be...jek/ kan jek

Partikel fatis merupakan partikel gabungan yang membentuk kalimat bantahan.
(18)Bentuk partikel Ngak seh

Partikel fatis ngak seh merupakan partikel fatis yang membentuk kalimat tanya digunakan untuk menanyakan sesuatu kepada lawan bicara.

\subsection{Bentuk Fatis Berjenis atau berupa kata}

Dari hasil penelitian yang telah dilakukan, ditemukan jenis fatis yang disebut satuan gramatik berupa kata. Berikut ini akan dipaparkan jenis fati berupa kata disertai dengan disertai fungsi penggunaanya.

\subsubsection{Kata fatis $n g g i h / a o k$}

Kata fatis $n g g i h$ bersinonim dengan kata aok yang berfungsi untuk memberikan kawan persetujuan kepada lawan bicara. Namun kata fatis nggih digunakan saat berbicara dengan lawan tutur yang usianya lebih tua. Sedangkan kata fatis aok digunakan untuk berbicara dengan lawan tutur yang sebaya atau yang lebih muda dari si penutur.

\subsubsection{Kata fatis banjur}

Kata fatis banjur digunakan saat bertemu atau berpapasan dengan kerabat di jalan maupun lewat di depan rumah. Kata fatis ini memiliki arti mamapir yang biasa di ucapakan untuk mengajak kerabat untuk mampir dirumah sebagai basa-basi saat 
kebetulan bertemu di jalan maupun di tempat lain.

\subsubsection{Kata fatis masihan}

Kata fatis masihan memiliki arti 'yang tersisa', kata fatis ini digunakan saat memberitahu lawan bicara bahwa sesuatu yang ingin digunakan itu tinggal tersisa sedikit, sehingga si pembicara melarang lawan bicaranya untuk menegur kawan bicaranya tersebut agar tidak menggunakannya.

\subsubsection{Kata fatis lasingan}

Kata fatis lasingan merupakan kata fatis seru yang digunakan untuk menekankan konstituen tertentu untuk mengekspresikan kekesalan dari pembicara terhadap lawan bicaranya.

\subsubsection{Kata fatis bemok}

Kata fatis bemok merupakan kata fatis yang digunakan sebagai kata penghubung dalam suatu percakapan yang memiliki arti lagi pula. Kata fatis ini digunakan pada saat bercerita tentang suatu kejadian yang pada dasarnya tidak dapat disesali kembali.

\subsubsection{Kata fatis keno}

Kata fatis keno merupakan kata fatis yang berfungsi untuk membentuk kalimat tanya. Kata fatis ini juga berfungsi untuk menanyakan kepastian kepada lawan bicara dan juga sebagai bentuk basa-basi kepada lawan bicara.

\subsubsection{Kata fatis lega}

Kata fatis lega merupakan kata fatis seru atau interjeksi yang menunjukkan ekspresi keheranan pembicara terhadap kawan bicara.

\subsubsection{Kata fatis teh/tekah}

Kata fatis teh/tekah memiliki arti ayo, yaitu digunakan untuk mengajak kawan bicara melakukan sesuatu. Kata fatis teh merupakan kependekan dari kata fatis tekah untuk mempersingkat pengucapan.

\subsubsection{Kata fatis halo}

Kata fatis halo digunakan untuk mengukuhkan pembicaraan, menyapa atau memulai kontak melalui telepon.

\subsubsection{Kata fatis amin}

Kata fatis amin digunakan untuk mengukuhkan ujaran kawan bicara. Biasanya saat kawan bicara mengucapkan do'a ataupun harapan.

\subsubsection{Kata fatis tabek}

Kata fatis tabek memiliki arti permisi. Kata fatis ini biasanya digunakan saat menyapa ataupun berjalan melewati seseorang yang usianya lebih tua sebagai bentuk penghormatan serta sopan santun terhadap lawan bicara.

\subsubsection{Kata fatis jamak}

Kata fatis jamak biasanya digunakan untuk menekankan makna kesangatan terhadap sesuatu dan sebagai bentuk ungkapan gambaran kemiripan suatu hal dengan hal lain. 


\subsection{Bentuk fatis berupa frase}

Bentuk frase fatis yang ditemukan pada daerah pentelitian di Dusun Bentek Desa Pemenang Barat adalah sebagai berikut.

1.3.1 Frase fatis $k u$ menjulu/ tekah $k u$ menjulu

Frase fatis diucapkan ketika seseorang berpamitan kepada kawan bicara. Penggunaan frase tekah $k u$ menjulu/ku menjulu digunakan saat pembicara berpamitan dengan kawan bicaranya dan untuk mengakhiri pembicaraan.

\subsubsection{Frase fatis meliwat juluk}

Frase fatis ini diucapkan atau digunakan saat seseorang memohon ijin untuk berjalan melewati rumah kerabat. Frase ini berfungsi untuk membuka pembicaraan sebagai bentuk basa-basi terhadap kawan bicara.

\subsubsection{Frase fatis terima kasih}

Frase fatis ini digunakan saat menerima sesuatu dari pembicara. Seperti dalam bahasa Indonesia, dialek Kuto-kute pun menggunakan frase terima kasih sebagai bentuk penghormatan terhadap lawan bicara ketika diberikan sesuatu.

\subsubsection{Frase fatis sabar wah}

Frase ini digunakan saat pembicara turut berduka cita atas peristiwa atau musibah yang di alami oleh kawan bicaranya.

\subsubsection{Frase fatis selamet ndeh}

Frase fatis ini di ucapkan saat pembicara merasakan kebahagiaan yang tengah dirasakan oleh lawan bicaranya sebagai bentuk rasa persahabatan.

\subsubsection{Frase fatis ya Allah}

Frase fatis ya Allah di gunakan saat pembicara merasa bimbang dan bertanya kepada diri sendiri atas musibah yang menimpanya.

\subsubsection{Frase fatis assalamu'alaikum}

Frase fatis ini digunakan saat memulai kontak dengan lawan bicara. Baik saat mengunjungi kerabat secara langsung kerumahnya ataupun pada saat menelpon maupuun menerima serta mengakhiri pembicaraan lewat telepon.

\subsubsection{Frase fatis wa'alaikumu salam}

Frase fatis ini biasanya digunakan saat menjawab frase fatis assalamu'alaikum yang berfungsi untuk memulai ataupun mengakhiri interaksi dengan lawan bicara.

\subsubsection{Frase fatis astagfirullah}

Frase fatis astagfirullah biasanya digunakan saat pembicara merasa kaget terhadap sesuatu.

\subsubsection{Frase fatis subhanallah}

Frase fatis subhanallah dipakai saat pembicara merasa kagum terhadap sesuatu. 


\subsubsection{Frase fatis insya Allah}

Frase fatis insya Allah digunakan saat pembicara menerima tawaran dari kawan bicaranya.

\subsubsection{Fase fatis allahu akbar}

Frase fatis ini biasanya digunakan saat pembicara merasa keheranan terhadap sesuatu hal.

\subsubsection{Frase fatis Alhamdulillah}

Frase fatis ini biasanya digunakan saat pembicara mendapatkan pemberian terhadap kawan bicara sebagai bentuk syukur terhadap pemberian yang diberikan.

\subsubsection{Frase fatis lailahaillallah}

Frase fatis ini digunakan saat pembicara merasa kesal terhadap lawan bicaranya.

\section{2) Fungsi Kategori Fatis pada Masyarakat Sasak}

Konsep fatis dibedakan berdasakan fungsinya: yaitu fungsi bahasa untuk memulai komunikasi, mempertahankan komunikasi dan menarik perhatian lawan bicara agar tetap memperhatikan pembicaraan, Jackobson (dalam Waridin 2008: 39). Fungsi fatis yaitu sebuah wacana berfungsi untuk membuka jalan atau kontak. Fungsi kategori fatis yang tedapat dalam dialek Kuto-kute pada masyarakat Dusun Bentek Desa Pemenang Barat.

\subsection{Fungsi untuk memulai percakapan}

Dalam dialek Kuto-kute pada masyarakat Bentek ditemukan fungsi kategori fatis yang digunakan untuk memulai percakapan. Penggunaan penggunaan kata fatis halo pada kalimat "halo, mbe kon dik?" dan frase “assalamu'alaikum, arak tau ite?" dalam dialek Kuto-kute digunakan sebagai kalimat untuk memulai percakapan. Hal ini menunjukkan fungsi kategori fatis untuk memulai percakapan seperti yang dikemukakan oleh Jackobson terdapat juga dalam dialek Kuto-kute. Selain dari fungsi untuk memulai percakapan bentuk peristiwa tutur di atas juga dapat dikategorikan sebagai fungsi untuk memecah kesenyapan dan untuk melakukan basa-basi.

\subsection{Fungsi untuk melakukan gosip}

Berikut ini adalah bentuk tidak tutur yang terdapat dalam dialek Kuto-kute yang digunakan untuk melakukan gosip dan fungsi fatis agar pembicaraan tetap berlangsung saat melakukan gosip.

\begin{tabular}{|c|c|}
\hline Aini & $\begin{array}{l}\text { :"Eh, tekan jek Leni ya } \\
\text { merangkat?”( hei, katanya } \\
\text { si Leni menikah?) }\end{array}$ \\
\hline Reni & $\begin{array}{l}\text { :"Aok, tekelem ya sik } \\
\text { paling!” (iya, semalam dia } \\
\text { diculik) }\end{array}$ \\
\hline & $\begin{array}{l}\text { :“Oh, sai poh kancanya? } \\
\text { Tau mbe?" (oh, sama } \\
\text { siapa?) }\end{array}$ \\
\hline
\end{tabular}


Pada peristiwa tutur di atas, frase "tekan jek" digunakan saat pembicara bertanya kepada lawan bicaranya apakah benar atau tidak kabar yang didengarnya, sehingga ia menanyakan hal itu kepada lawan bicaranya. Hal tersebut menunjukkan frase "tekan jek" merupakan frase yang berfungsi untuk melakukan gosip dengan lawan bicara. Kemudian frase "taon dik kenoh" Juga merupakan frase yang muncul atau yang digunakan ketika melakukan gosip dengan lawan bicara. Jadi fungsi kategori fatis untuk melakukan gosip yang dikemukakan oleh Jackobson dalam teorinya terdapat juga dalam dialek Kuto-kute.

\subsection{Fungsi untuk mengalihkan topik}

Fungsi fatis yang ditemukan selanjutnya yaitu untuk mengalihkan topik serta mengalihkan perhatian lawan bicara ke hal lain. Berikut ini peistiwa tutur yang digunakan untuk mengalihkan topik pembicaraan.

Indra : :Ngak jek lega sering dik geran? Aok wah kah melemak adeng-adeng tan jauk motor!" (mengapa sering sekali kamu kecelakaan? Ya sudah, besok hati-hati mengendarai motor!)

Doni :“Aok!” (iya)

Tindak tutur Indra mengandung frase aok wah kah. Frase ini berfungsi mengalihkan topik. Sebelumnya Indra menanyakan mengapa Doni sering mengalami kecelakaan. Selanjutnya Indra memberikan nasehat kepada Doni agar Doni lebih berhati-hati.

\subsection{Fungsi untuk menyatakan empati}

Dalam dialek Kuto-kute, terdapat fungsi fatis yang digunakan untuk menyatakan empati, berikut peristiwa tutur yang digunakan untuk menyatakan empati. Berikut peristiwa tutur yang digunakan untuk menyatakan empati.

$$
\begin{aligned}
& \text { Musa }: \text { Sabar aok polong, } \\
& \text { ihlasang wah lokak nu. } \\
& \text { Insyaallah ya ulek dalam } \\
& \text { keadaan khusnul khatimah. } \\
& \text { Apalagi ya ngenangang pas } \\
& \text { kenjekak sembahyang } \\
& \text { subuh lek mesjid. (sabar ya, } \\
& \text { ikhlaskan beliau. Insyaallah } \\
& \text { beliau meninggal dalam } \\
& \text { keadaan khusnul khatimah. } \\
& \text { Apalagi beliau meninggal } \\
& \text { ketika sholat shubuh di } \\
& \text { mesjid) } \\
& \text { Fadoli : Aok polong, makasih wah } \\
& \text { dateng menukak bapakku. } \\
& \text { (iya saudara, teima kasih } \\
& \text { sudah datang } \\
& \text { memamakamkan bapakku) }
\end{aligned}
$$

Pada percakapan pertama tedapat dua bentuk jenis fatis yaitu klausa "sabar wah polong" dan "ihlasang wah" yang berarti memberikan empati kepada lawan bicara yang sedang berduka cita atas kematian orang tua dari temannya.

\subsection{Fungsi untuk mengungkapkan \\ kesantunan}

Di dalam dialek Kuto-kute, fungsi kategori fatis yang digunakan sebagai 
ungkapan kesantunan terdapat dalam peristiwa tutur berikut.

Bapak :"nak, baitang bapak gergaji lek gerobak no". (nak tolong ambilkan bapak gergaji di gerobak itu)

Anak :"Nggih bapak, anteh semendak tiang baitang" (iya bapak, tunggu sebentar, saya ambilkan)

Lia :"Tabek bapuk, tiang meliwat juluk" (permisi nenek, saya lewat dulu)

Bapuk :"Mbe ke lain dik no?, banjur apa juluknya" (hendak kemana? Ayo mampir dulu)

Lia :"Ne tiang lalo bak balen Pak Kadus" (ini saya hendak ke rumah Pak Kadus)

Bapak :"Oh, aok tiaknya pak kadus jek, lokah dik dapetnya (oh, iya pak kadus ada, sudah hampii saja)

Dari peristiwa tutur di atas, terdapat penggunaan kata fatis "nggih" pada percakapan pertama yaitu ketika sang anak menjawab seruan bapaknya, si anak menggunakan kata fatis "nggih" sebagai bentuk kesantunannya kepada orang tua. Selain itu pada percakapan kedua, tedapat kata "tabek" yang digunakan saat melewati orang yang lebih tua, hal ini biasa digunakan dalam masyarakat Dusun Bentek sebagai bentuk ungkapan sopansantun kepada lawan tutur yang usianya lebih tua. Jadi dapat disimpulkan, dalam dialek Kuto-kute terdapat fungsi kategori fatis yaitu berupa kata "nggih" dan "tabek" yang digunakan sebagai ungkapan kesopanan.

\subsection{Fungsi sebagai penegasan}

Di dalam dialek Kuto-kute, terdapat fungsi kategori fatis yang digunakan sebagai penegasan dalam percakapan yang memiliki makna sebagai penjelas, menghaluskan perintah, menekankan kesalahan lawan bicara, menekankan kepastian, menekankan konstituen tertentu, menekankan alasan, menekankan maksud, menekankan bantahan, menekankan ajakan, menekankan pemberian kepada lawan bicara, menekankan permintaan kepada lawan bicara, menekankan makna kesangatan, menekankan kemiripan sesuatu hal dengan hal lain, menekankan pembuktian, menekankan pemberitahuan, untuk menciptakan rasa nyaman, memberi persetujuan, membenarkan lawan bicara serta menegaskan kalimat tanya, memaksa dengan cara membujuk, dan bentuk pengukuhan terhadap ujaran lawan bicara.

Berikut adalah peristiwa tutur yang digunakan sebagai penegasan terhadap proses atau kronologi suatu kejadian.

R :'Kumbek epe poh buk?" (ibu kenapa )

I :"Kan tenek tiang bak teben lalo arisan kanca bapak, laguk kami geran kon udayana nabrak montor kijang lek mudi. Ya ampoknya keseleo ima ne" (tadi ketika saya dalam perjalanan untuk pergi arisan, saya dan 
bapak jatuh di jalan udayana menabrak mobil kijang dari belakan dan terjatuh sehingga tangan saya keseleo)

Ujaran Ibu yang merupakan kalimat berita yang mengandung pemberitahuan kepada remaja mengenai alasan tangannya keseleo dengan cara menceritakan proses yang menyebabkanya terjatuh. Dalam percakapan tersebut, terdapat bentuk patikel kan yang digunakan sebagai penegas dalam menceritakan proses atau kronologi suatu kejadian.

\subsection{Fungsi untuk mengungkapkan ekspresi}

Di dalam dialek Kuto-kute, fungsi kategori fatis yang digunakan untuk mengungkapkan ekspresi, misalnya tanda keheranan, tanda pembicaraan menerima sesuatu dari lawan bicara, tanda pembicara menerima sesuatu yang menyenangkan, tanda merasa bimbang atau ungkapan keragu-raguan, tanda kekesalan, tanda pembicara mendapat tawaran dari lawan bicara, sebagai bentuk kekhawatiran. Berikut peristiwa tutur yang digunakan sebagai bentuk ekspresi atau tanda keheranan.

Anak 1 :“Lega pelok bak ono!” (takut sekali gadis itu!)

Anak 2 :“Aok eh!” (iya yah!)
Tindak tutur anak 1 pada peristiwa tutur di atas memperlihatkan keheranan anak 1 terhadap apa yang telah dilihatnya. Jadi, kata fatis lega pada peristiwa tutur di atas dapat berfungsi sebagai ungkapan ekspresi keheranan.

\subsection{Fungsi untuk mengakhiri percakapan}

Wujud fatis yang membangun fungsi mengakhiri kontak adalah kata fatis assalamumu' alaikum, wa'alaikumu salam dan kata fatis teh/tekah, ku menjulu. Berikut ini peristiwa tutur yang mengandung kata fatis assalamumu' alaikum wa'alaikumu salam dan kata fatis teh/tekah, ku menjulu dengan fungsi untuk mengakhiri kontak. Seperti pada kutipan percakapan di bawah ini.

$$
\begin{array}{cl}
\text { Ida :"Melemak senen ku } \\
\text { kete ampok, Assalamu } \\
\text { 'alaikum." (besok hari } \\
\text { senin saya kesini lagi, } \\
\text { Assalamu 'alaikum) } \\
\text { Ririn :"Aok, Wa'alaikum } \\
\text { salam." (iya, } \\
\text { wa'alaikum salam) }
\end{array}
$$

Pada peristiwa tutur di atas, terilhat fungsi frase fatis serapan assalamu'alaikum untuk mengakhiri kontak antara pembicaran dan kawan bicara. Ida mengucapkan assalamu 'alaikum untuk mengakhiri pertemuannya dengan Ririn. 
3) Stategi Penggunaan Bentuk dan Fungsi Kategori Fatis pada Masyarakat Sasak

Hasil penelitian tentang fungsi kategori fatis dalam dialek Kuto-kute Dusun Bentek Desa Pemenang Barat Kecamatan Pemenang Kabupaten Lombok Utara yaitu, untuk memulai percakapan, untuk melakukan gosip, untuk mengalihkan topik, untuk menyatakan empati, untuk mengungkapkan kesantunan, sebagai penegasan, fungsi untuk mengungkapkan ekspresi dan fungsi untuk mengakhiri percakapan. Berdasarkan fungsi kategori fatis tersebut, maka peneliti dapat mengklasifikasikan strategi kesantunan penggunaan kategori fatis dalam dialek Kuto-kute Dusun Bentek Desa Pemenang Barat Kecamatan Pemenang Kabupaten Lombok Utara menjadi dua, yaitu strategi kesantunan positif dan negative. Bentuk dari strategi kesantunan negative dan positif tersebut akan diuraikan secara terperinci sebagai berikut.

1. Fungsi kategori fatis untuk memulai percakapan dalam strategi kesantunan lebih cenderung menggunakan strategi kesantunan positif dengan mengintensifkan perhatian penutur dengan mendramatisasikan peristiwa dan fakta.
2. Fungsi kategori fatis untuk melakukan gossip dinilai menggunakan strategi kesantunan positif dengan menunjukkan hal-hal yang dianggap mempunyai kesamaan melalui basa-basi (small talk) dan praanggapan (presupposition)

3. Fungsi kategori fatis untuk mengalihkan topik dinilai menggunakan strategi kesantunan positif dengan menhindari ketidaksetujuan dengan pura-pura setuju dalam arti persetujuan yang semu.

4. Fungsi kategori fatis untuk menyatakan empati dinilai menggunakan strategi kesantunan positif dengan membesar-besarkan perhatian, persetujuan, dan simpati kepada mitratutur.

5. Fungsi kategori fatis untuk mengungkapkan kesantunan dinilai menggunakan strategi kesantunan negatif dengan ujaran tindak tutur itu sebagai kesantunan yang bersifat umum.

6. Fungsi kategori fatis sebagai penegasan dinilai menggunakan strategi kesantunan positif dengan mengintensifkan perhatian penutur dengan mendramatisasikan peristiwa dan fakta 
7. Fungsi kategori fatis untuk mengungkapkan ekspresi dinilai menggunakan strategi kesantunan positif dengan dinilai menggunakan strategi kesantunan positif dengan mengintensifkan perhatian penutur dengan mendramatisasikan peristiwa dan fakta

8. Fungsi kategori fatis fungsi untuk mengakhiri percakapan dinilai menggunakan strategi kesantunan positif dengan menyatakan hubungan secara timbal balik.

\section{SIMPULAN DAN SARAN}

Berdasarkan tujuan penelitian yang ingin dicapai dan hasil serta pembahasan penelitian yang telah dipaparkan pada bab sebelumnya, dapat disimpulkan hal-hal berikut.

1) Bentuk kategori fatis dalam dialek Kuto-kute pada masyarakat Dusun Bentek Desa Pemenang Barat Kecamatan Pemenang Kabupaten Lombok Utara yaitu: partikel, kata dan frase.

2) Fungsi kategori fatis dalam dialek Kuto-kute Dusun Bentek Desa Pemenang Barat Kecamatan Pemenang Kabupaten Lombok Utara yaitu, untuk memulai percakapan, untuk melakukan gosip, untuk mengalihkan topik, untuk menyatakan empati, untuk mengungkapkan kesantunan, sebagai penegasan, fungsi untuk mengungkapkan ekspresi dan fungsi untuk mengakhiri percakapan.

3) Nilai dari strategi kesantunan penggunaan bentuk dan fungsi kategori fatis bahasa Sasak, yaitu menggunakan srategi kesantunan negatif dan strategi positif.

Dialek Kuto-kute merupakan salah satu khasanah budaya bahasa Indonesia di tanah air yang perlu di teliti baik dari segi struktur bahasanya maupun dari segi lainnya. Berkaitan dengan hal tersebut, disampaikan saran ssebagai berikut.

1) Kepada masyarakat penutur, maupun pemerintah daerah serta pusat, hendaknya lebih mencurahkan perhatiannya terhadap bahasa, karena bahasa mencerminkan budaya.

2) Aspek kategori fatis dapat diteliti lebih terperinci, khususnya mengenai fungsi dan makna kategori fatis pada objek lain, misalnya dalam lirik lagu ataupun yang lainnya. Tentu penulis menaruh harapan besar kepada peneliti berikutnya. 


\section{DAFTAR PUSTAKA}

Arikunto, Suharmini. 2009. Manajemen Penelitian. Jakarta: Rineka Cipta.

Holmes, Janet. Tanpa Tahun. An Introduction to Sosiolinguitics (Terjemahan). Tidak Diterbitkan.

Kridalaksana, Harimurti. 2001. Kamus Linguistik. Jakarta: Gramedia Pustaka Utama.

. 2008. Kelas Kata dalam Bahasa Indonesia. Jakarta: Gramedia.

Leech, Geoffrey. 1982. Prinsip-prinsip Pragmatik (Terjemahan). Jakarta: Universitas Indonesia.

Mahsun. 2011. Metode Penelitian Bahasa:

Tahapan, Strategi, Metode, dan Tekniknya. Jakarta: PT. Raja Grafindo Indonesia Persada.

Moleong, J Lexy. 2004. Metodologi Penelitian Kualitatif. Bandung: PT Remaja Rosdakarya.

Pranowo. 2012. Berbahasa Secara Santun. Yogyakarta: Pustaka Pelajar.

Prayitno, Harun Joko. 2010. "Perwujudan Prinsip Kerja Sama, Sopan Santun, dan Ironi Para Pejabat dalam Peristiwa Rapat Dinas di Lingkungan Pemerintahan Kota Berbudaya Jawa" dalam jurnal terakreditasi Kajian Linguistik dan Sastra, Volume 22, No.1, Juni 2010, Jurusan Pendididkan Bahasa Inggris dan Indonesia FKIP UMS.

2011. Kesantunan Sosiopragmayik: Studi Pemakaian Tindak tutur direktif di Kalangan Andik SD Berbudaya Jawa. Surakarta: Muhammadiyah University Press Universitas Muhammadiyah Muhammadiyah Surakata.
Suandi, I Nengah. 2008. Pengantar Metodologi Penelitian Bahasa. Singaraja: Universitas Pendidikan Ganesha.

Sugiyono. 2010. Metode Penelitian Pendidikan: Pendekatan Kuantitatif,Kualitatif, dan $R \& D$. Bandung: Alfabeta.

Sukardi. 2004. Metodologi Penelitian Pendidikan (Kompetensi dan Praktiknya). Jakarta: PT Bumi Aksara.

Waridin. 2008. Ungkapan Fatis dalam Acara Temu Wicara Televisi. Tesis. Jakarta: Fakultas Ilmu Pengetahuan Budaya UI. Tidak Diterbitkan. 
Jurnal Ilmiah Telaah Vol. 3 No. 1, Januari 2018 